\title{
RESEARCH
}

\section{Trends in the Number of Authors and Institutions in Papers Published in AJPE 2015-2019}

\author{
Sarah Plummer, PharmD, ${ }^{\mathrm{a}}$ Jennifer Sparks, PharmD, ${ }^{\mathrm{a}}$ Kimberly Broedel-Zaugg, PhD, MBA, ${ }^{\mathrm{a}}$ Daniel A. \\ Brazeau, PhD, ${ }^{\mathrm{b}}$ Kristine Krebs, MPS, ${ }^{\mathrm{c}, \mathrm{d}}$ Gayle A. Brazeau, PhD ${ }^{\mathrm{a}, \mathrm{e}}$ \\ ${ }^{a}$ Marshall University, School of Pharmacy, Huntington, West Virginia \\ ${ }^{\mathrm{b}}$ Marshall University, Joan C. Edwards School of Medicine, Huntington, West Virginia \\ ${ }^{c}$ American Association of Colleges of Pharmacy, American Journal of Pharmaceutical Education, Arlington, Virginia \\ ${ }^{\mathrm{d}}$ American Society for Microbiology, Washington, District of Columbia \\ ${ }^{\mathrm{e}}$ Editor, American Journal of Pharmaceutical Education, Arlington, Virginia
}

Corresponding Author: Gayle A. Brazeau, Marshall University, School of Pharmacy, One John Marshall Dr., Huntington, WV 25755. Tel: 304-696-7390. Email: brazeau@marshall.edu

Submitted November 22, 2021; accepted February 25, 2022; ePublished February 2022

Objective. To investigate the number of authors and unique institutions per paper published in the American Journal of Pharmaceutical Education (AJPE) in 2015-2019, and to examine the number of authors and unique institutions for papers that were nominated for the Rufus A. Lyman Award in the same period.

Methods. Articles published in AJPE from 2015 through 2019 were reviewed. Data collected for each article included article type, number of authors, and number of institutions.

Results. Of the 811 articles published in AJPE during this period, the number of authors increased significantly from an average of 3.5 (1.8) to 4.5 (2.2). The number of unique institutions also increased significantly from 1.7 (1.1) to 2.4 (1.8). Conclusion. There is a trend toward a greater number of authors and unique institutions for the publications in one pharmacy education journal. Explanations for this trend may include pressure to publish, increased research complexity, and expanded interprofessional collaboration.

Keywords: authorship, journals, institutions, publishing, AJPE

\section{INTRODUCTION}

In the past few decades, the average number of authors per paper published in the scientific and health science disciplines has been trending upward resulting in group authorship becoming the norm and single authorship the exception. The New England Journal of Medicine (NEJM), focused on publishing the highest quality evidence for advancing medical sciences and improving patient care, noted that from 1975 to 1989, the mean number of authors increased from four to six and the number of papers with single authors decreased from $9 \%$ to $3 \% .{ }^{1}$ For scientific papers indexed in PubMed from 1975 to 2016, the mean number of authors jumped from 1.9 to 5.7 per paper. ${ }^{2}$ In the Journal of the American Medical Association, Lancet, and NEJM, the median number of authors per article increased from a range of 8-11 in 2005 to 11-18 in 2015. ${ }^{3}$ In pharmacy practice journals such as the American Journal of Health-System Pharmacy, Annals of Pharmacotherapy, and Pharmacotherapy, there has been a similar trend in the number of authors per article over time, with fewer single-author papers seen in 1989, 1999, and 2009. ${ }^{4}$

Success in academia is associated with the number and frequency of papers one has published in high-impact, peer-reviewed journals. This results in a "publish or perish" culture in which there is immense pressure for academics and scholars to produce frequent publishable research to advance their career. ${ }^{5}$ This high-pressure environment is generally pervasive at primarily research institutions. ${ }^{6}$ Additionally, pharmacy education and accreditation has increasingly emphasized the importance of scholarly productivity in our colleges/schools of pharmacy with the importance of demonstrating an environment that promotes and evaluates the quality and quantity of faculty scholarly productivity in the biomedical sciences, pharmaceutical sciences, clinical sciences, socio-administrative sciences and the scholarship of teaching and learning (SOTL). ${ }^{7}$ As such, one of the most convenient methods for assessing faculty scholarly productivity is by looking at the number of papers they have published in journals with a high impact factor, though it should be noted that the methods for assigning impact factors have changed over the tenure of most faculty.

With increased faculty research obligations, more opportunities in interdisciplinary and interprofessional research collaboration, and the evolution of multi-discipline studies, the trend has changed to group authorship reflecting an emphasis toward collaborative research. The heightened emphasis on collaboration across the pharmacy academy combined with an increased focus on SOTL may explain the growth in the number of authors and unique institutions per 
paper further emphasizing a "publish together or perish" culture. This study was conducted to investigate whether there is a similar trend of increased number of authors and unique institutions in the papers associated with SOTL in pharmacy published in the American Journal of Pharmaceutical Education (AJPE).

The two-fold objectives of this study were to investigate the number of authors and unique institutions per paper published in AJPE between 2015 and 2019, and to examine the number of authors and unique institutions for papers that were nominated for the Rufus A. Lyman Award. The Rufus A. Lyman Award is presented annually by the American Association of Colleges of Pharmacy to the author(s) of the best paper published in AJPE in the preceding year. We specifically investigated these nominated manuscripts as they are considered the best papers because of their utility and significance to pharmacy education, originality, research methodology and analysis, and writing style. This study may provide insight for investigators and administrators considering the appropriate numbers of individuals and organizations to be included and the type of manuscript which will be considered a significant addition to the literature. ${ }^{8}$

\section{METHODS}

The study involved the manual review of papers published in AJPE from 2015 (Volume 79) through 2019 (Volume 83) and the papers nominated for the Rufus A. Lyman Award during the same timeframe. ${ }^{8.9}$ The number of authors and unique institutions was recorded and counted for each article for each year. The papers were classified according to the following article types: Commentary, Education/Research Brief, Innovations in Teaching, Instructional Design and Assessment (IDA), Research, Review, Special Article, Statement, Teachers' Topics, Theme Issue, Viewpoint, and Viewpoint/Counterpoint. All these article types were peer reviewed. Letters to the Editor were excluded from this study as these are not peer reviewed and are published in response to previously published papers as a forum for the expression of ideas or for commenting on matters of interest. Unique institutions included pharmacy colleges/schools, health science centers, hospitals, clinical centers, and research institutes. We considered branch campuses and the main campus as one college/school of pharmacy.

A master data set was developed to evaluate changes in the number of authors or the number of unique institutions as a function of year for all the article types and for the Lyman Award-nominated papers. A second analysis was conducted for research papers only. Analysis of variance was conducted as a function of year of publication for both the number of authors and the number of unique institutions using Statistica (TIBCO Software Inc.). Post-hoc analysis was not conducted as the goal was to investigate trends in the number of authors and unique institutions. Values are expressed as mean and standard deviation with $p<.05$ considered statistically significant.

\section{RESULTS}

There were 811 papers published across these article types from 2015 to 2019 . The number of published papers identified per year were 143 (2015), 161 (2016), 154 (2017), 136 (2018) and 217 (2019). The number of authors ranged from one to 18 with a Mean (SD) of 4.0 (2.3). The number of institutions ranged from one to 14 with a Mean (SD) of 2.0 (1.7). The number of papers nominated each year for the Lyman Award were 20 (2015), 21 (2016), 26 (2017), 28 (2018) and 32 (2019). For Lyman Award-nominated papers, the number of authors ranged from one to 12 with a Mean (SD) of 4.7 (2.2) and the number of institutions associated with these authors ranged from one to eight with a Mean (SD) of 2.2 (1.6).

Table 1 lists the number of published papers for each article type. The largest number of papers published based on article type was Research (386), followed by IDA (107), and Commentary (94). The number of authors for manuscripts addressing scholarly research and assessment (Research, IDA, and Education/Research Brief) had approximately four authors and two institutions (average range of 4.1 to 4.4 for authors and 1.4 to 2.1 for unique institutions). The largest number of authors and unique institutions with an average of 6.6 authors and 4.4 institutions was in the theme issue papers followed by special article with an average of 6.0 authors and 4.5 unique institutions. Editorial pieces, such as viewpoints, commentaries, and viewpoints/counterpoints had a Mean (SD) of 1.7 (0.8), 2.6 (2.0), and 1.6 (1.6) for authors and 1.3 (0.8), 2.0 (1.6), and 1 (0) for the number of unique institutions, respectively.

From 2015 to 2019 for all article types, the number of authors increased significantly at an average of 3.5 (1.8) to 4.5 (2.2) (Figure 1A). The number of unique institutions also increased significantly from 1.7 (1.1) to 2.4 (1.8) over the same timeframe. However, in 2018, the number of authors and unique institutions decreased from 4.1 (2.6) to 3.4 (2.2) and 2.2 (2.0) to 1.7 (1.3), respectively.

The number of research papers per year were 51 (2015), 70 (2016), 76 (2017), 54 (2018) and 135 (2019) (Figure 1B). An analysis of only research papers did not show a statistical increase in the number of authors over the years $(p=.13)$, Mean (SD) of 4.1 (1.8) in 2015 and 4.6 (2.0) in 2019. However, there was a statistically significant increase in the number of unique institutions from 2.1 (1.4) to 2.3 (1.6) between 2015 to 2019 ( $p=.01$ ). As with all papers, there was still 
a significant decrease from 2017 to 2018 in both the number of authors $(p=.05)$ and the number of unique institutions $(p=.009)$.

A review of the nominated Lyman Award papers showed there was no statistical change in the number of authors and unique institutions during the study period (Figure 2). The range in the average number of authors was 4.4 to 5.3 and the range in the average number of unique institutions was 1.7 to 2.7 in 2015-2019. Research papers were the largest category of Lyman Award-nominated papers with $62 \%$ in $2015,76 \%$ in $2016,57 \%$ in $2017,79 \%$ in 2018 , and $81 \%$ in 2019. However, no statistical difference was seen in the average number of authors (range 4.3 to 4.9 ) and unique institutions (range 1.8 to 2.6 ).

\section{DISCUSSION}

Across multiple disciplines, the number of authors per paper has been steadily rising over the past several decades. ${ }^{10-12}$ Likewise, our study, which focused on one pharmacy education journal, AJPE, showed a statistically significant increase in the number of authors per paper over a 5-year period.

The National Library of Medicine published a report on the number of authors per Medline/PubMed citation noting several factors that may account for the increasing trend of group authorship. ${ }^{2}$ One factor could be the policy related to author names in Medline has changed with time. For example, the personal author limit has changed from 10 (1983) to 25 (1996) and then completely removed in 2000. ${ }^{2}$ According to MEDLINE, a personal author is listed when the author names appear in the article byline. Alternatively, they can be listed anywhere in the text or as members of a writing group or writing committee. ${ }^{13} \mathrm{We}$ considered all individuals who were listed in the byline of AJPE papers as personal authors.

Another factor is the emphasis placed on the number of manuscripts one must publish in peer-reviewed journals to be considered for promotion and/or tenure dossiers in higher education. Dixon and colleagues reported on pharmacy practice chairs' scholarship productivity as quantified by their publication metrics, including their total publications, publications per year, total citations, citations per publication, h-index and M quotient. ${ }^{14} \mathrm{~A}$ higher scholarship productivity was noted in chairs with a higher faculty rank, those in public institutions, those whose institution was part of a health science center, those whose institution was considered an R1 Carnegie Classification, those whose institution was listed as a top 25 National Institute of Health funding ranks using the Blue Ridge Institute for Medical Research, and those whose institution had a higher US News and World Report ranking. ${ }^{14}$ Given the importance of these metrics in maintaining a school's reputation, chairs with a higher publication metrics may also be essential in stimulating their colleagues to enhance their own publication record by serving as a mentor or having connections to work with at other institutions.

In pharmacy education, the heightened emphasis on SOTL leads to the desire to invite students and residents/fellows to participate in our research endeavors and may account in part for the increased number of authors. While this practice teaches students, residents, and fellows to learn how to conduct appropriate research and how to work in a team, a potential disadvantage is determining who should be credited for authorship and who should be recognized in the acknowledgments section. The International Committee of Medical Journal Editors (ICMJE) defines the term "author." ICMJE recommends that authorship be based on the following criteria: substantial contributions to the conception or design of the work; or the acquisition, analysis, or interpretation of data for the work; and drafting the work or revising it critically for important intellectual content; and final approval of the version to be published; and agreement to be accountable for all aspects of the work in ensuring that questions related to the accuracy or integrity of any part of the work are appropriately investigated and resolved. ${ }^{15}$ Students pursuing PGY1 residencies, PGY1 residents pursuing PGY2 residencies, and residents/post-doctoral fellows pursuing academic careers realize the importance of their names on scholarly publications as essential to being selected for these positions may push for authorship when their contributions may not merit authorship credit. The extent of authorship or recognition should be discussed with these students, residents and post-doctoral fellows as the study design is being developed and implemented.

The increase in the number of unique institutions could be the result of expanded collaborations across universities. The AJPE instructions to authors emphasize the importance of manuscripts to be of broad interest to the academy versus on single institutions or programs. ${ }^{16}$ AJPE encourages submissions that are broad in scope, rather than local (one school) or regional (localized area or country) as this will expand the interest of the readership. ${ }^{16}$ In addition, the number of institutions (hospitals, medical centers, ambulatory clinics, etc.) associated with a college/school of pharmacy has risen due to the need for more affiliations to provide the required clinical introductory and advanced pharmacy practice sites in the doctor of pharmacy program. ${ }^{7}$ This results in a larger number of pharmacy practice clinicians, both faculty and non-faculty members, who may be involved in enhancing pharmacy education and SOTL. In contrast, Tilak and colleagues suggested that the growth in authorship in medical publications reflects inflationary growth in the number of authors rather than the increased complexity of the research. ${ }^{12}$ 
The focus on interprofessional teaching and practice in pharmacy education could also contribute to increases in authors and unique institutions. In addition, increased specialization in clinical practice, biomedical sciences, pharmaceutical sciences, and biostatics/study design will require greater professional expertise only available through collaborations with other individuals and institutions resulting in an increased number of research and teaching collaborations through large health care networks that drive up the total number of authors and institutions. The 20132014 AACP Academic Affairs Report and the 2014-2015 Argus Commission Report emphasized the importance of big data, academic analytics and learning analytics. ${ }^{17,18}$ The use of these larger data sets across institutions could lead to a larger number of authors and unique institutions. There is also a greater focus on building communities across various institutions to support student learning and programmatic assessment, ${ }^{19-21}$ team-based learning, ${ }^{22}$ experiential learning ${ }^{23-25}$ and interprofessional experiential education. ${ }^{26}$

The number of authors and unique institutions for the Lyman Award-nominated papers did not change over this period. Most of these nominated papers were research papers. A limited number of authors and unique institutions could result in a study design that is more focused in its objectives and goals, thus leading to stronger results, discussion, and conclusions in the paper. These findings also could result from the sample size for Lyman Award-nominated papers being much smaller (an average of 25 per year) likely resulting in less power to detect a significant change over these selected years.

Discussion continues in the literature around the topics of authorship and allocation of credit, particularly when there are multidisciplinary teams across various organizations and institutions. Various professional societies, universities, and journals have developed guidelines and best practices for whom and when an individual should be considered for authorship. ${ }^{27,28}$ This is becoming more important as SOTL continues to expand with the advancements in pharmacy education, with more pharmacy colleges/schools, and with the importance of scholarly activities in pharmacy programs. This often results in larger research teams across multiple institutions and organizations. It is critical to determine at the start of any research project that may result in a scholarly manuscript who is to be credited for their contributions and authorship. Individuals who do not meet ICMJE's authorship ${ }^{15}$ criteria should be listed in the acknowledgments section to be fair and ethical to those who have either planned or performed the research and participated extensively in the writing of the manuscript. The implications of these findings suggest that AJPE should consider requiring the specific contributions of the authors either in the submission process or as a specific section of the manuscript. Furthermore, perhaps the academy should consider alternative methods of recognition for outstanding scholarly publications that result from greater collaborations and interprofessional cooperation as this is becoming an expectation for programming at associations' annual meetings or alternatively, limit the number of individuals and institutions involved with submissions of these programming ideas. ${ }^{29}$

The first limitation of this study is that it only reviewed five years of data from one pharmacy education journal. A second limitation is that the number of unique institutions was based upon the authors' decision to separate health care networks and clinics from pharmacy colleges/schools. As such, this might increase the number of institutions depending upon what the authors indicated in their own affiliations. The authors also note the slight decline in 2018 in the number of authors and unique institutions, which could be a function of the total number of manuscripts submitted from 2017 to 2018 decreased by $15 \%$ (data not shown).

\section{CONCLUSION}

In this small study that examined the number of authors and unique institutions in one scholarly pharmacy education journal, a similar trend was seen in the increase in the number of authors and institutions in peer-reviewed publications over a 5-year period. This is consistent with trends seen in other scholarly journals from professional associations and societies. In pharmacy education, these findings indicate a trend for publications to include a group of authors from various institutions as a function of the increased complexity of the research questions requiring the expertise and perspective of several individuals and institutions. In addition, there is an increased focus on the importance of AJPE manuscripts to be of broad interest to the academy versus single institutions and that submissions for annual meeting programming encourages a diversity of individuals. ${ }^{16,29}$ Authorship should be based upon significant contributions from individuals responsible for planning the research, performing the research, and the intellectual contributions to the writing of the final manuscript.

\section{REFERENCES}

1. Sobal J, Ferentz KS. Abstract creep and author inflation. N Engl J Med. 1990;323:488-489. https://www.nejm.org/doi/full/10.1056/NEJM199008163230718. Accessed November 16, 2021.

2. US National Library of Medicine. Number of authors per MEDLINE/PubMed citation. Updated May 15, 2020. https://www.nlm.nih.gov/bsd/authors1.html. Accessed November 16, 2021. 
3. Fontanarosa P, Bauchner H, Flanagin A. Authorship and team science. JAMA. 2017;318(24):2433-2437. https://jamanetwork.com/journals/jama/fullarticle/2667044. Accessed November 16, 2021.

4. Dotson B, McManus KP, Zhao JJ, Whittaker P. Authorship and characteristics of articles in pharmacy journals: changes over a 20-year interval. Ann Pharmacother. 2011; 45:357-363.

https://journals.sagepub.com/doi/10.1345/aph.1P610. Accessed November 16, 2021.

5. Baethe G. Publish together or perish. Dtsch Arztebl Int. 2008;105(20):380-383.

https://www.aerzteblatt.de/int/archive/article/60236. Accessed November 16, 2021.

6. Moosa IA. Publish or Perish. 2018. Cheltenham, UK: Edward Elgar Publishing Ltd. https://doi.org/10.4337/9781786434937. Accessed November 16, 2021.

7. Accreditation Council for Pharmacy Education. Accreditation standards and key elements for the profession program in pharmacy leading to the doctor of pharmacy degree ("Standards 2016"). https://www.acpeaccredit.org/pdf/Standards2016FINAL.pdf. Accessed November 16, 2021.

8. American Journal of Pharmaceutical Education. Rufus A. Lyman Award. https://www.aacp.org/resource/rufuslyman-award. Accessed November 16, 2021

9. American Journal of Pharmaceutical Education. Archive of all content. https://www.ajpe.org/content/by/year. Accessed November 16, 2021.

10. Norris RP. Authorship patterns in CJNR: 1970-1991. Scientometrics. 1993;28(2):151-158, https://doi.org/10.1007/BF02016897. Accessed November 16, 2021.

11. King Jr JT. How many neurosurgeons does it take to write a research article? authorship proliferation in neurosurgical research. Neurosurgery. 2000;47(2):435-440. https://academic.oup.com/neurosurgery/articleabstract/47/2/435/2931589?redirectedFrom=fulltext. Accessed November 16, 2021.

12. Tilak G, Prasad V, Jena AB. Authorship inflation in medical publications. Inquiry: The Journal of Health Care Organization, Provision, and Financing. 2015;52: July 29,2015:1-4. July 29, 2015. https://doi.org/10.1177/0046958015598311. Accessed November 16, 2021.

13. National Library of Medicine. Authorship in Medline. https://www.nlm.nih.gov/bsd/policy/authorship.html. Accessed November 16, 2021.

14. Dixon D, Sobieraj DM, Brown RE, Koenig RA, Wagner M, Baker WL. A bibliometric analysis of peer-reviewed journal publications of pharmacy practice department chairs. Am J Pharm Educ. 2021;85(8):8481.

15. International Committee of Medical Journal Editors. Defining the role of authors and contributors. http://www.icmje.org/recommendations/browse/roles-and-responsibilities/defining-the-role-of-authors-andcontributors.html. Accessed October 24, 2021.

16. American Journal of Pharmaceutical Education. Submission process. https://www.ajpe.org/page/about/submissionprocess. Accessed October 24, 2021.

17. Cain J, Conway JM, DiVall MV, et al. Report of the 2013-2014 Academic Affairs Committee. Am J Pharm Educ. 2014;78(10): Article S23. https://doi.org/10.5688/ajpe7810S2. Accessed November 16, 2021.

18. Baldwin JN, Bootman JL, Carter RA, et al. Pharmacy practice, education, and research in the era of big data: 2014-2015 Argus Commission report. Am J Pharm Educ. 2015;79(10): Article S26. https://doi.org/10.5688/ajpe7910S26. Accessed November 16, 2021.

19. Janke KK, Seaba HH, Welage LS, et al. Building a multi-institutional community of practice to foster assessment. Am J Pharm Educ. 2012;76(4): Article 58. https://doi.org/10.5688/ajpe76458, Accessed November 16, 2021.

20. Janke KK, Kelley KA, Sweet BV, Kuba SE. A modified Delphi process to define competencies for assessment leads supporting a doctor of pharmacy program. Am J Pharm Educ. 2016;80(10): Article 167. https://doi.org/10.5688/ajpe8010167. Accessed November 16, 2021.

21. Janke KK, Kelley KA, Martin BA, Ray ME, Sweet BV. Identifying high-impact and managing low-impact assessment practices. Am J Pharm Educ. 2019;83(7): Article 7496. https://doi.org/10.5688/ajpe7496. Accessed November 16, 2021.

22. Whitley HP, Bell E, Eng M, et al. Practical team-based learning from planning to implementation. Am J Pharm Educ. 2015;79(10): Article 149. https://doi.org/10.5688/ajpe7910149. Accessed November 16, 2021.

23. Vos S, Kooyman C, Feudo D, et al. When experiential education intersects with learning disabilities. Am J Pharm Educ. https://doi.org/10.5688/ajpe7468. Accessed November 16, 2021.

24. Kieser M, Feudo D, Legg J. Accommodating pharmacy students with physical disabilities during the experiential learning curriculum. Am J Pharm Educ. Published online April 2021. https://doi.org/10.5688/ajpe8426. Accessed November 16, 2021. 
25. Assemi M, DiVall MV, Lee K, Sy E, O’Sullivan T. Quality assurance and improvement practices of experiential education programs in schools of pharmacy. Am J Pharm Educ. 2019;83(3): Article 6582. https://doi.org/10.5688/ajpe6582. Accessed November 16, 2021.

26. Grice GR, Thomason AR, Meny LM, Pinelli NR, Martello JL, Zorek JA. Intentional interprofessional experiential education. Am J Pharm Educ. 2018;82(3): Article 6502. https://doi.org/10.5688/ajpe6502. Accessed November 16, 2021.

27. American Psychology Association. Publication practices and responsibilities. https://www.apa.org/research/responsible/publication. Accessed November 16, 2021.

28. Institute of Medicine. On Being a Scientist: A Guide to Responsible Conduct in Research. 2009. Third Edition. Washington, DC: The National Academies Press. Authorship and allocation of credit, pp. 35-38. https://doi.org/10.17226/12192. Accessed November 16, 2021.

29. Pharmacy Education 2022 Submission Information. https://www.aacp.org/article/pharmacy-education-2022submission-information. Accessed February 16, 2022. 
Figure 1A. Number of Unique Institutions and Authors over Time for all paper categories (Mean + SD). The number of unique institutions and the number of authors increased significantly over these years $(p<.05)$.

Figure 1B. Number of Institutions and Authors over Time for Research papers (Mean +SD). The number of unique institutions increased significantly over the years $(p<.05)$. There was no statistical significance in the number of authors over these years.
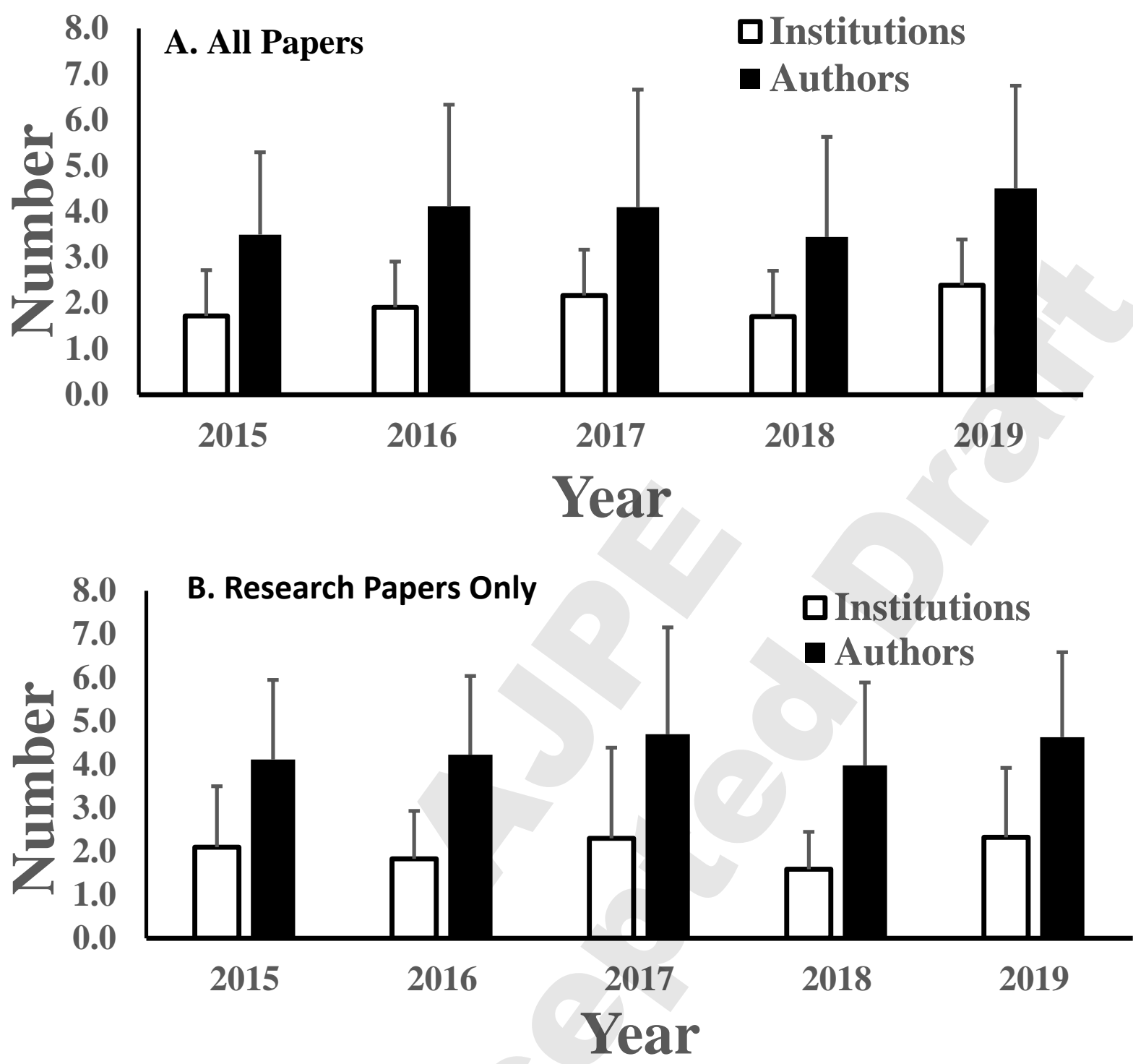
Figure 2. Number of Unique Institutions and Authors over Time for papers nominated for the Rufus A. Lyman Award. There was no statistically significant difference in the number of unique institutions and authors over these years.

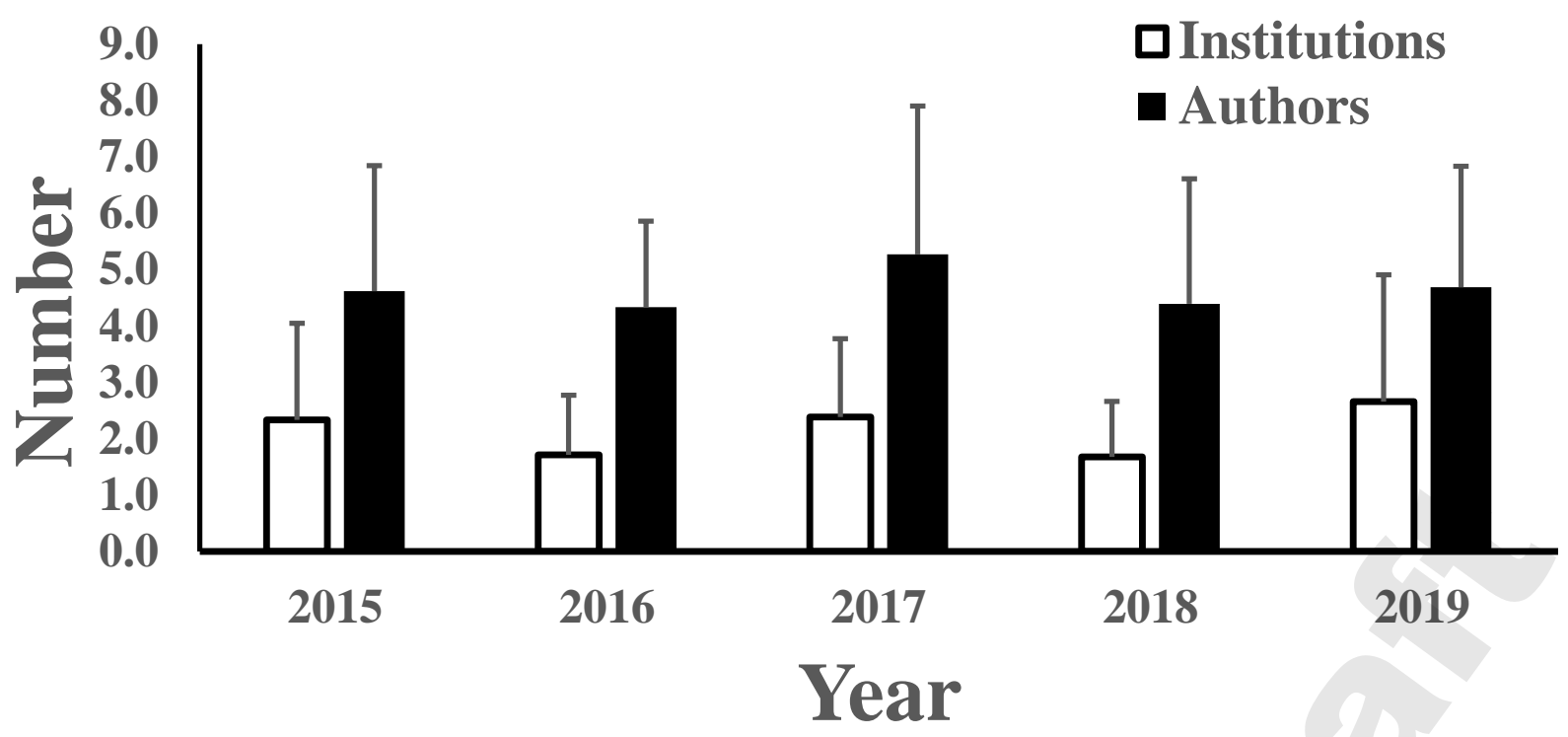


Table 1. Number of Authors and Unique Institutions for manuscript categories from 2015-2019. There is a statistical difference between the various categories in the number of authors and unique institutions across the categories.

\begin{tabular}{llll}
\hline Manuscript Categories & N & $\begin{array}{l}\text { Number of } \\
\text { Authors } \\
\text { Mean (SD) }\end{array}$ & $\begin{array}{l}\text { Number of Unique } \\
\text { Institutions } \\
\text { Mean (SD) }\end{array}$ \\
\hline Commentary & 94 & $2.6(2.0)$ & $2.0(1.6)$ \\
Education/Research Brief & 76 & $4.1(2.2)$ & $1.6(1.3)$ \\
Innovations in Teaching & 2 & 6.5 & 1.0 \\
Instructional Design and Assessment & 107 & $4.3(2.0)$ & $1.4(0.6)$ \\
Research & 386 & $4.4(2.0)$ & $2.1(1.5)$ \\
Review & 53 & $3.3(1.9)$ & $2.3(2.0)$ \\
Special Article & 11 & $6.0(4.0)$ & $4.5(4.0)$ \\
Statement & 15 & $4.7(3.4)$ & $3.4(3.4)$ \\
Teacher's Topics & 16 & $2.8(1.3)$ & $1.2(0.6)$ \\
Theme Issue & 13 & $6.6(3.2)$ & $4.4(2.7)$ \\
Viewpoint & 30 & $1.7(0.8)$ & $1.3(0.8)$ \\
Viewpoint/Counterpoint & 10 & $1.6(1.6)$ & $1.0(0)$ \\
\hline
\end{tabular}

